\title{
Measuring the Influence of Web Features in the Online Gamification Environment: A Multimediation Approach
}

\author{
Mishal Hasnain Naqvi $\mathbb{D}^{1},{ }^{1}$ Sun Guoyan $\mathbb{D}^{2},{ }^{2}$ and Muhammad Hasnain Abbas Naqvi $\mathbb{D}^{3}$ \\ ${ }^{1}$ School of Business, Sichuan University, Chengdu, China \\ ${ }^{2}$ School of Accounting, Nanjing Audit University, China \\ ${ }^{3}$ School of Economics and Management, Southwest Jiaotong University, Chengdu, China
}

Correspondence should be addressed to Sun Guoyan; guoyansun@126.com

and Muhammad Hasnain Abbas Naqvi; hasnainnaqvi@my.swjtu.edu.cn

Received 4 February 2020; Revised 29 October 2020; Accepted 19 November 2020; Published 4 January 2021

Academic Editor: Jesus Fontecha

Copyright (C) 2021 Mishal Hasnain Naqvi et al. This is an open access article distributed under the Creative Commons Attribution License, which permits unrestricted use, distribution, and reproduction in any medium, provided the original work is properly cited.

\begin{abstract}
Considering the increasing importance of user experience and the influence of gamification techniques in the online business environment. This research explores the antecedents and outcomes of user experience in the context of website features. We proposed a multimediation conceptual framework integrating several constructs to test the user response about online gamification. This study used PLS-SEM to measure the direct and mediating relationship among hedonic features and utilitarian features user experience, monetary value, experiential value, satisfaction, and behavioral consequences in the online gamification environment. The findings indicate that hedonic features and utilitarian features directly affect user experience, further influencing user satisfaction, intention to use, and recommendation. Moreover, experiential value and monetary value also have a significant effect on user experience and user satisfaction. The study also confirmed the mediating effect of user experience, monetary value, experiential, and user satisfaction. Hence, this study's results can help web managers provide users' memorable experiences of using such gamification websites, which in turn increase their satisfaction and arouse expected behavioral intentions.
\end{abstract}

\section{Introduction}

In recent years, business success has become a competitive task linked with customer experience apart from considering product pricing and differentiation [1]. Integrating eretailing strategies with customer experience can result in significant performance outcomes $[2,3]$. However, numerous studies have researched online shopping on developing and maintaining an online user experience, still requiring research scholars and online retailers [4, 5]. For retailers, transferring user experience from offline to online shopping environment is challenging, particularly for those that successfully create a positive experience of shopping offline. One possible way retailers can increase online user experience and create an interactive and appealing platform of shopping is through the use of gamification techniques [6]. The notion of gamification is a fast-growing mechanism in marketing and online retailing [7]. Since marketing is based on attraction, manipulation, and persuasion; therefore, this technique has a great scope in marketing [6]. Gamification can attain customers' attention through entertainment, and appealing game techniques also create value for marketers. The rapid increase in customer switching behavior due to intense competition in the online marketplace calls for a change in the e-business environment [7]. To improve consumer behavior, there is a need to pay more attention to positive customer experience than the marketing mix. Now, delivering values to the customer is the key concern of online businesses. Therefore, to ensure and sustain user experience, many firms, for instance, Recycle Bank, McDonald's, Pepsi, Samsung, and Nike, use gamification techniques for effective communication. Many other websites, such as Twitter, eBay, Facebook, and integrated game mechanics, enhance user engagement [8]. Game mechanics can be used to create standardize service for customers, but limited scholars have explored this phenomenon in services marketing $[5,9]$. 
Online business is a very lucrative field which is based on both technology and service marketing. To maximize the customer experience and engagement, retailers must incorporate attractive methods [10]. Existing literature reported the direct effect of gamification techniques on social network platforms, which encourage user behavior to stick with the relationship being developed on the particular social networks [11]. Such positive feedback indicated the effective use of gamification techniques to create a memorable user experience and build a perception of the product or service value and thus achieve satisfaction.

Examining the customer experience and the values they perceived in an online marketing context is very important because consumer behavior (satisfaction, purchase intention, and willingness to pay price premium) can be appropriately measured through perceived value and user experience. Although existing literature in this regard still lacks a framework to predict and explain how the gamification techniques influence customer experience and satisfaction in online retailing $[12,13]$. Consequently, marketing scholars and practitioners have to investigate what strategy can be adopted to improve consumer satisfaction and experience in a gamification shopping environment [8]. Since gamification techniques are growing in E-business, channelize shopping as an entertainment activity for customers. There is a need to measure how customer perceived behavior, experience, and satisfaction can be affected by game techniques. As these factors greatly contribute to the success of the online business, a more comprehensive approach is sorely required to gauge the effectiveness of these techniques [8].

Consistent with the ideas mentioned above, such a challenging rationale has stimulated the interest of scholars and develops curiosity for further investigation on this topic. The association between gamification and user experience has not been sufficiently addressed. Despite the importance of game mechanics in online consumer response, existing literature showed some limitations. However, game techniques in online browsing reflect a great potential to increase customer satisfaction but have not gained much academic consideration. The present research is aimed at bridging this window of opportunity and developing a comprehensive framework to examine the mediating effect of user experience and satisfaction towards the online gamification context. We proposed a multimediation conceptual model by integrating several constructs for consumer response about online gamification. Our study used a unique approach to deal with this question: does user experience and satisfaction towards online gamification mediates the relationship between website features, intention to use, and recommendation? Moreover, the growing emphasis on gamification in business also generates the need to measure its effect quantitatively.

Another significant contribution of this study is identifying the influence of website features on user experience and how they affect the user's perceived value and satisfaction. Since many unpredictable changes have been witnessed in the business environment, our study will investigate how to escalate positive user experience to deliver the expected value in the form of commodities that ultimately impact the behavioral intention and encourage the recommendation of online shopping to potential customers. Lastly, our study results would lay a foundation for e-business managers to validate and refine their gamification strategies to avoid risk.

1.1. Gamification as an Essential Element of Marketing. Gamification can be characterized as the utilization of game mechanics and game design methods in nongame settings to form behavior, to create skills, and to involve individuals in innovation [14]. To affect individuals' motivation and experience to resolve complex tasks, to execute specific activities, or simply to have leisure time [15]. Some scholars defined it as a new perspective of analyzing, designing, and enforcing solutions in a business environment [16]. Innovation has traditionally been related to business and marking environment, offering a way out to rapidly complete the tasks. Game techniques, procedures, and frameworks usually used to impact and propel people, gatherings, or networks are presently being utilized to drive behavior and produce anticipated impact and results $[17,18]$. These applications are also used to transforming user interaction into expressive and quantifiable business commitments [19]; at the same time, minimizing the prospective barrier to technology use and offering genuine positive business sway [20]. Gamification can motivate user behavior, assist, and encourage users to perform different activities empowered through services delivered by the organization [13]. Subsequently, gamification has received significant prominence in marketing. As per Hamari [21], gamification applications are a sort of selling, service-driven, and advertising philosophy that enables service administrators to instruct and urge users to develop an in-depth interest in this technique.

\section{Literature Review}

2.1. The Relationship between Website Features and User Experience. Consumers assess a product or service based on the information, images, and online reviews of customers when they shop online [22]. As recognized by Fischer and Arnold [23, 24], a customer while shopping online (website) focuses both on utilitarian and hedonic shopping perspectives. Similarly, the website interface, color, design, scheme, and product classification strongly affect consumer decision-making [23]. O'Brien [24] suggested two possible orientations of website shopping: (i) hedonic shopping: when the purpose of using a website is to achieve enjoyment through online experience; and (ii) utilitarian shopping: which is mainly based on attaining a specific goal, for instance, purchasing a product/service [25, 26]. Hence, consumer satisfaction is based on whether or not the product or service fills his/her utilitarian or hedonic needs during the use of the website for shopping [27]. The investigation of Sheng and Teo [28] revealed the terminology of "user experience" coins by Pine II and Gilmore [29] in their book named "experience economy." They perceived a new version of economic gain; one can get after consuming certain commodities. According to the existing literature, user experience is a state of interaction between customers and goods, which is based on gaining satisfaction [30,31]. Additionally, user experience is an overall evaluation of a product or service that 
relies on what a user desire and what he/she received. User experience is not just related to purchasing a commodity. It is a multilevel and comprehensive approach to product and consumer interaction at several levels. So, the concept of user experience is holistic and derived from the theory of consumption, which tends to explain an individual's experience or interaction with the company through its market offerings [30]. Based on this notion, value creation not only includes merchandising unforgettable experiences but also permits users to cherish the remarkable instants of affiliation with the organization in a more unique way [31]. Customers cocreate their distinctive experience with the company results in the formation of "experience" [32]. More precisely, a good user experience engages the user at different levels of the value cocreation process. Verhoef et al. [33] reported that user experience is a holistic concept that consists of many responses; for instance, the user's physical, emotional, cognitive, social, and affective demeanor. Thus, perceiving user experience is a difficult feeling, and it is complex to differentiate the response of various components as there may be interrelations and overlapping paths. $\mathrm{Hu}$ and O'Brien $[24,34]$ concluded that user experience involves both hedonic features and utilitarian features. In the context of e-commerce, the customer always seeks appealing website design because it adds fun and enjoyment (hedonic features) to the online shopping experience and also leads to possible consumption or purchase of a commodity (utilitarian feature) suggested by $[27,35]$. Specifically, the addition of such features in product formation can develop a long-lasting relationship with the user. The emotional pleasure can be evoked and lead to product engagement, provided that the product is embraced by such characteristics. Moreover, close emotional ties and customer loyalty can also be achieved using these features [22], which ultimately results in a positive user experience. Based on the above literature, we proposed the hypotheses:

H1. utilitarian features have a direct positive impact on user experience.

H2. Hedonic features have a direct positive impact on user experience.

H1a. Utilitarian features and experiential value is mediated by user experience.

H1b. Utilitarian features and monetary value is mediated by user experience.

H2a. Hedonic features and experiential value is mediated by user experience.

2.2. The Relationship between Perceived Value and User Experience. Perceived value is a very rich construct frequently used to understand market behavior [36]. Perceived value is recognized as a strong evaluation indicator for business [37]. The definition of perceived value defined by Zeithaml [38] is "an overall assessment of the utility of a product based on perceptions of what is received and what is given." It draws a comparison between economic/monetary and functional benefits with sacrifices. Lee [39] explained that the product/service's perceived value is a source of interaction between product and consumer. According to Gummerus [40], a comprehensive and holistic experience may support a phenomenological perspective to value research. However, the critical approach is to measure the perceived value multidimensional construct [41] to target an experiential method of value supported by the cognitive affective-behavior notion. This approach is most extensively used in service and tourism research [42]. Many scholars have considered perceived value as an essential component to measure behavior [43]. Thus, keeping in view the nature and context of the present research, we choose to measure the relationship of monetary and experiential value with the consumer shopping experience. The nature of consumer perceived value from various dimensions is essential to understand [41]. Therefore, to investigate the consumer experience, monetary, and experiential perspective is necessary to understand. Previous studies reported monetary value as a critical indicator to measure online shopping behavior [44]. It further elucidates that value is delivered to the consumer in the form of a product or service purchase at a low price [45]. Thus, the consumer shopping experience will profoundly influence in terms of monetary perspective [42].

Moreover, when the customer receives a quality product or service and pays less money, this produces an affirmative perceived value [46]. Parallel with the investigation of Lee [39], the present research implies experiential value based on pleasure, enjoyment, and a sense of fulfillment gained from browsing a gamification website. Moreover, an experiential value perspective does exist in service marketing research [39]. Based on the above information, a comprehensive conceptualization of perceived value will be used in this research. The explanation of the perceived value proposed by [38] is "the overall assessment of the utility of a product based on the perceptions of what is received and what is given." Based on this definition, the present research proposes that acquiring value is simply a trade-off between benefits and risks associated with online shopping. Keeping in view the user experience regarding online shopping, the need is to address how it influences consumer perception regarding value. The existing literature showed a strong relationship between user experience and value. We assume that a positive user experience can significantly affect perceived value, as it is an overall assessment of a product or service. Gentile et al. [45] points out that a positive, multidimensional, and holistic user experience ensures value for both customer and service providers. Besides, bringing value offers an enduring experience and provides customers an influential association with a company. According to Hsu et al. [22], customers can affect the value cocreation process. Based on this discussion, we choose two important conceptualization of perceived value (monetary and experiential) for this research.

Moreover, the present research advocates that consumers want to escalate their online shopping experience value by 
managing the trade-offs regarding probable advantages contrasted with threats that have been identified in online shopping. Finally, creating value for customers is not only meant to be trading with experience but also empowers customers to develop a life-long relationship with the company. The company must welcome the customer's input regarding a product or service orientation to ensure this bonding. Thus, we propose the following hypotheses:

H3. user experience has a significant positive impact on experiential value.

H4. user experience has a significant positive impact on monetary value.

H3a. user experience and user satisfaction is mediated by experiential value.

H4a. user experience and user satisfaction is mediated by monetary value.

2.3. The Relationship between User Experience and Satisfaction. User experience allows people to gain familiarity with the technology that channelizes people's communication with products or service providers [47] as users become aware of a particular technology and get experience, which encourages them to perceive the maximum use of technology exchange information online [5]. A significant user experience results in the satisfaction of using such technology. According to Oliver [48], satisfaction is a consumer opinion about a product or service having sensory and emotional attributes to achieve consumer satisfaction. Murphy et al. [49] demonstrated that user leisure shopping experience is closely associated with customer satisfaction. Apart from the product or services, website features for online shopping mean a lot for a customer. The convenient, user-friendly, attractive, and fun-filled features of the website would help develop a positive user experience and be an essential satisfaction [50]. According to Limayem and Cheung [51], online purchase experience can increase customer knowledge and familiarity with goods and services, ranging from tourism, banking, and hotel booking services. User experience played an important role and influenced prospective online behavior [52]. Previous studies indicated that significant user experience could be a substantial factor in gaining satisfaction. Thus, we proposed the hypotheses:

H5. user experience has a significant positive impact on satisfaction.

H5a. monetary value and recommendation is mediated by user satisfaction.

2.4. Role of Perceived Value and User Satisfaction. Satisfaction is a user's emotional state of mind developing from an evaluation and comparison between its expectations and actual performance [53]. In contrast, perceived value has been described as a complete evaluation of a product or service concerning price and social or experiential perspective [25].
Broadly, perceived value is expressed as a cognitive construct dealing with the gains and sacrifices. However, satisfaction is the process of a practical evaluation [51, 52]. Hence, perceived value is considered as an antecedent of satisfaction. Numerous studies have provided a strong association between perceived value and satisfaction [54-56]. Nowadays, customer-perceived value is a powerful indicator of measuring satisfaction $[57,58]$; besides, companies generate value based on competitive advantage such as inculcating desired perceived value, which satisfies the customer and affects their behavioral intention to buy the product $[26,59]$. According to Lempinen and Rajala [60], technology-driven research needs to examine the relationship between perceived value and commerce outcome value. Two essential perspectives of perceived value that are monetary and experiential are incorporated to measure satisfaction to address this proposition.

Similarly, this study used perceived value dimensions as an antecedent of satisfaction, whereby satisfaction has a vital significance on recommendation and behavioral intention $[61,62]$. These outcomes act as a different set of responses and influence the ongoing connection between customers and the firm [63]. This study emphasizes that customer value is a combination of two essential factors, relationship benefit and service delivery, and suggests that satisfaction, which is the state of attainment of specific needs or wants, is a product of transactional exchange between the firm and the customer $[48,63]$. Notably, the contrast of value divulges that customers' evaluation of a product or service value may have a strong connection with satisfaction formation [64]. The customer tends to choose a commodity that they assume to have the desired cost against money and keep all the benefits.

Moreover, keeping in view this research, the experiential value derived from happiness and sense of achievement acquired from using the gamification website. Lee et al. [39] also confirmed that experiential value is a necessary construct in service marketing, generating consumer satisfaction. Finally, perceived value has a substantial contribution to forming satisfaction for technology use. Thus, to broaden consumer satisfaction towards the gamification website, perceived value can be an essential forecaster. Base on the above evidence, we proposed the following hypotheses:

H6. Monetary value has a direct positive impact on satisfaction for the gamification website.

H7. Experiential value has a direct positive impact on satisfaction for the gamification website.

2.5. Satisfaction and Recommendation. The recommendation is an indicator of the user's positive behavior who is satisfied with the service they acquired $[65,66]$. The recommendation describes the positive valence of word of mouth on potential customers about new technology and encourages them to use it. Many authors propose a recommendation for a very strong variable used to measure the actual behavior of users $[62,67]$. The existing literature on website shopping suggests a positive relationship between customer satisfaction and recommendation of a product/service. According to the prospect theory, people are loss averse. One unit of loss can 
have a more substantial effect as compared to one unit of gain. We extend the reasoning of reference [68] and suggest that the intensity of risk is less in recommending a product/service than to buy a product/service through the website without knowing its credibility and authenticity. Recommending a service to potential customers cost less risk and more chance of getting a reliable outcome. So, parallel to prospect theory, we predict that customer satisfaction from e-service would strongly recommend the prospective users to use it. Based on the above facts, we proposed the hypotheses:

H8. satisfaction has a significant positive impact on the recommendation.

2.6. Satisfaction and Continuance Intention. The expectation confirmation theory is widely used in buying behavior literature to investigate users' continuance intention for using technology apps [53]. Much of the literature on IT is focused on users' acceptance and continuance intention. According to Jin et al. [69], satisfaction has a great significance on continuance intention. From the perspective of continuance intention of e-commerce sites, [69] explored that satisfaction is a significant predictor of continuance intention. Based on the above literature, the following hypotheses have been proposed:

H9. Satisfaction has a significant positive impact on continuance intention.

We assumed that gamification has strong integration with customer behavior, affecting the antecedents and consequences of user experience. A proposed multimediation model has shown in Figures 1 and 2, respectively, to achieve a proper understanding of the research's primary theme.

\section{Methodology}

3.1. Sampling and Data Collection. We used a web-based survey to approach online users. Initially, invitations through emails were sent to the respondents for their participation and link to the survey website hosting the survey. The respondents were requested to give their opinions about the gamification application. The data was collected through a questionnaire survey using a convenience sampling technique because the respondents' population was not known. According to Burns and Bush [70], the survey method is useful to gather quantitative information compared to other qualitative techniques ably; besides, they stated that common themes could be surmised through statistical investigation grounded on primary data through the questionnaire survey method. Comparatively, since the sample proportion of qualitative techniques is not equivalent to the sample size of quantitative techniques, this type of data set is unfit for statistical examination. The questionnaire started with a brief introduction to the research topic to create a basic understanding of the nature of the study among the targeted audience. Another reason for providing such an explanation is to grab the respondents' maximum attention regarding the precision of their responses. Since gamification is a new concept in the context of user experience, it is highly important to give a pertinent explanation of the topic and clarify the interest of the researcher in gathering information regarding the experience of users towards gamification of the website. A total of 380 questionnaires were used to collect valuable responses. We also announced prizes for respondents on the successful completion of the survey to ensure quality feedback about using the gamification website. After excluding incomplete and poorly filled questionnaires, 310 valid questionnaires were used for data analysis and interpretation.

3.2. Scale Development. This research used validated items from already existing studies using a 5-point Likert-type scale. The acquired items were marginally modified as per the requirement of the research. All the items score ranging from 1 (strongly disagree) to 5 (strongly agree). The hedonic features and utilitarian features have been modified from the study of [27]. Additionally, monetary value and the experiential value were measured using the items taken from $[58,71]$. This research used the items of [72] and reference $[73,74]$ for analyzing user experience and user satisfaction. Intention to use has been calculated through the items of $[43,59]$. The recommendation was examined through the items taken from [75] study. The academicians and industry experts have carefully reviewed all the modified items. The questionnaire was further refined (grammatical changes, use of exact words, and terms) based on the expert's and academicians' feedback. We first conducted a pilot study on 30 respondents and considered the validity and reliability results.

Table 1 elaborates on the demographic distribution of the participants. A total of 310 valid responses were used for analysis. In terms of gender status, there were 159 males and 151 females out of the total participants.

\section{Measurement Model Assessment}

For the evaluation of the model, convergent validity and discriminant validity has been checked. Composite reliability [76] and rho indexes [77] are considered appropriate internal consistency methods. As per Gadermann et al., [78] Cronbach's alpha cannot be measured for reliability because it was not considered suitable for PLS-SEM. The (AVE) of the constructs and factor loadings was checked to assess the convergent validity $[79,80]$. Additionally, AVE's square root values and correlation among constructs have been compared to assess discriminant validity. The values of factor loading $>0.707$ [80], CR $>0.7$ [76], rho $>0.7$ [77], and AVE $>0.5$ [79] were above the required values and full filled the proposed requirements $[76,81]$ (Table 2).

Furthermore, Fornell-Larcker test was used to measure discriminant validity/divergent validity. The correlation values among constructs have to be less than 0.85 [82]. Similarly, we found the more excellent square root value of Average Variance Extracted for all constructs compared to the measurements of correlation among the constructs [83] (see Table 3). 


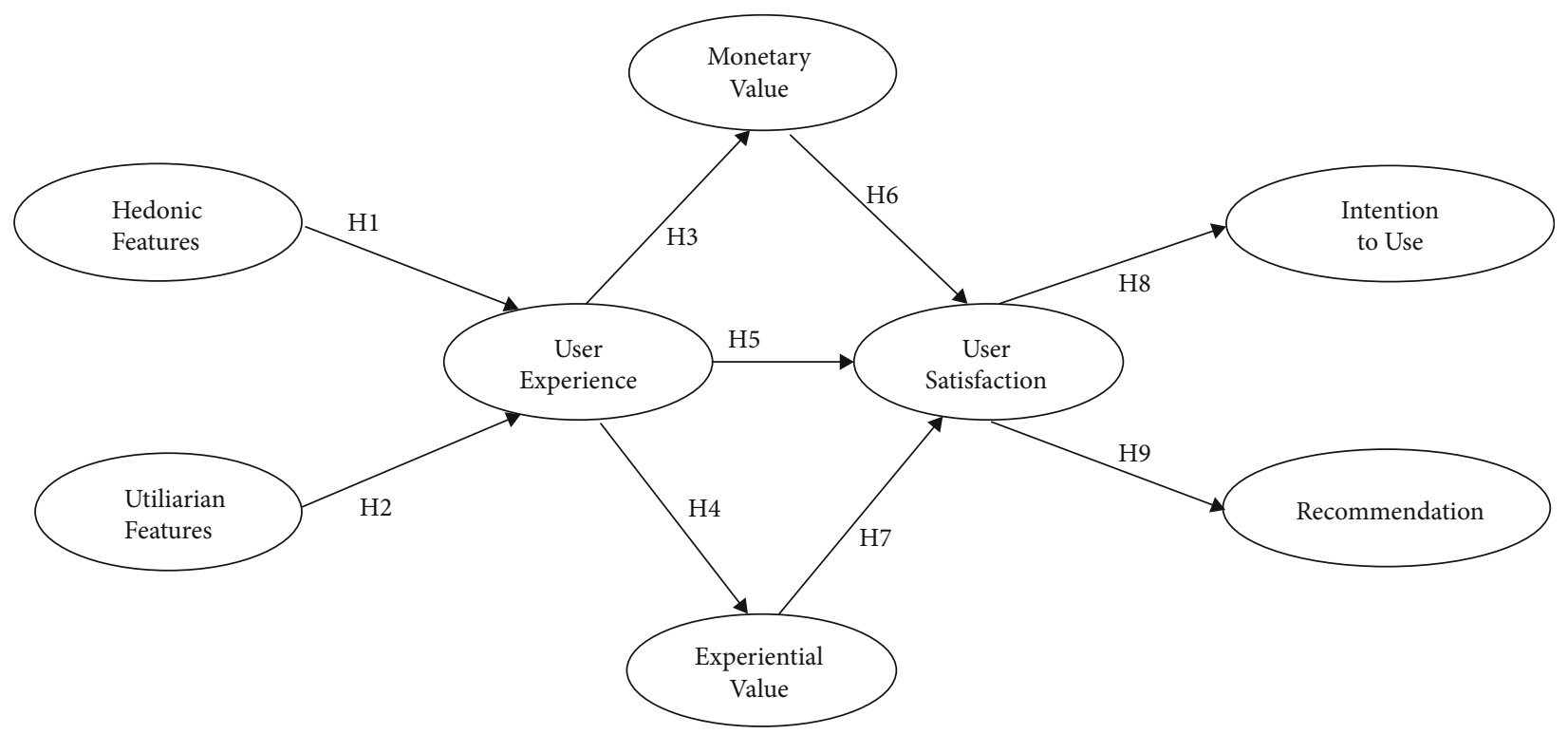

Figure 1: Conceptual model.

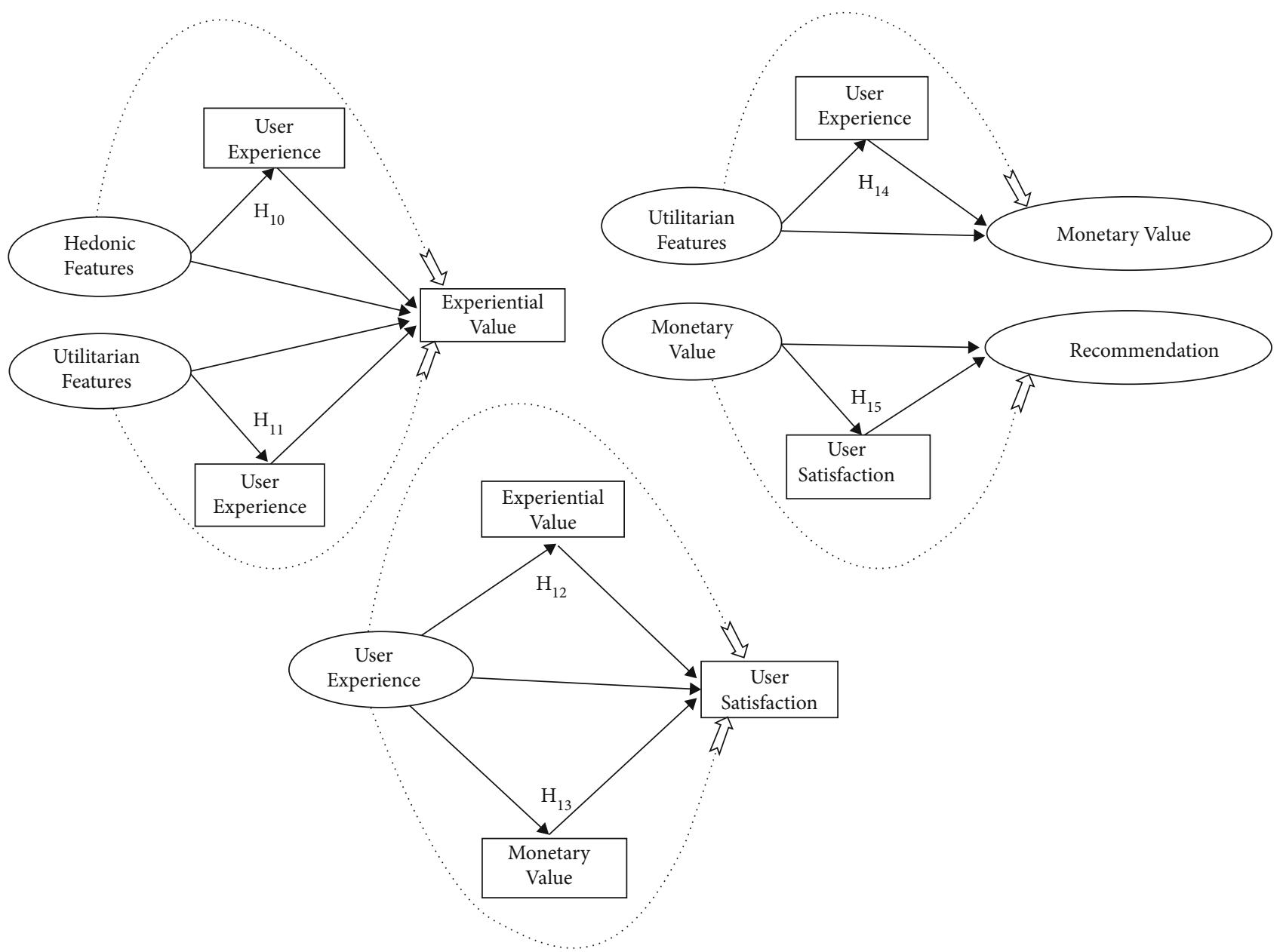

FIgURE 2: Multimediation models. 
TABle 1: Demographics of the respondents (310).

\begin{tabular}{lccc}
\hline & Frequency & Percent & Cumulative percent \\
\hline Gender & & & \\
$\quad$ Male & 159 & 51.29 & 51.29 \\
Female & 151 & 48.71 & 100 \\
Age & & & \\
$15-24$ & 270 & 87.10 & 87.10 \\
$25-34$ & 29 & 9.35 & 96.45 \\
$35-44$ & 5 & 1.61 & 98.06 \\
45 or above & 6 & 1.94 & 100 \\
Education & & & \\
$\quad$ Undergraduate & 244 & 78.71 & 78.71 \\
Masters & 66 & 21.29 & 100 \\
\hline
\end{tabular}

4.1. Structured Model Assessment. Table 4 shows the results of the direct effects of the hypotheses, as established in Figure 3, besides the complete measurement of the model suitable for more suitable representation. The exogenous variables indicated a significant antecedent with respect to their endogenous variables. Particularly, hedonic features positively predicts user experience $(\mathrm{H} 1: b=0.537, p<0.05, t$ value $=11.16)$. Utilitarian features significantly affect the user experience $(\mathrm{H} 2: b=0.250, p<0.05, t$ value $=4.816)$. Additionally, user experience has a positive influence on monetary value $(\mathrm{H} 3: b=0.700, p<0.05, t$ value $=17.889)$, experiential value (H4: $b=0.676, p<0.05, t$ value $=16.259)$, user satisfaction $(\mathrm{H} 5: b=0.223, p<0.05, t$ value $=3.695)$. Additionally, monetary value also put an affirmative and substantial influence on user satisfaction (H6: $b=0.398, t$ value $=6.680$, $p<0.05)$. Experiential value was significantly related to user experience (H7: $b=0.218, p<0.05, t$ value $=3.512)$. Consequently, user satisfaction positively and favorably influenced intention to use (H8: $b=0.549, p<0.05, t$ value $=10.519)$, and recommendation (H9: $b=0.518, p<0.05, t$ value $=$ 9.352). Hence, all hypotheses were supported.

As per Henseler et al. [84], the standardized root mean square residual is measured in PLS-SEM for the goodness of fit measure to evade the research framework's redundancy. $\mathrm{Hu}$ and Bentler, [85] precisely similar to [86], explained "the standardized difference between the observed correlation and the predicted correlation." Thus, standardized root mean square residual has been applied for the calculation of the global model fit. Based on the proposal of reference [84, 85 ], the standardized root mean square residual range can be 0.07 , under 0.08 . So, the anticipated strength of a structured framework can be tested by investigating the coefficient of determination $\left(R^{2}\right)$ values that signified the mutual influence of exogenous variables on endogenous variables. The values of $R^{2}$ can be projected with the following formula [87]:

$$
R^{2}=\sum_{j} \mid \widehat{\beta_{j}} \operatorname{cor}\left(\eta_{i}, \xi_{j}\right),
$$

where $\operatorname{cor}\left(\eta_{i}, \xi_{j}\right)$ is the latent construct, and $\beta_{j}$ is a factor of the structure model which signifies the connection concern- ing to $\eta_{j}$ and $\xi a_{i}$. The values of $R^{2}=0.25,0.50$, and 0.75 denote to frail, moderate, and robust, respectively [73]. The research model elucidated $45.5 \%$ of the user experience variance, $48.8 \%$ of the monetary value, $45.6 \%$ of the experiential value, $56.9 \%$ of user satisfaction, $29.5 \%$ of intention to use, and $26.8 \%$ of recommendation. The $R^{2}$ values were somewhat moderate and considerable [80].

4.2. The Effect Size and Predictive Relevance. Based on the perspective of reference [76], the $Q^{2}$ values were measured to assess the research framework's projective significance and precision. The value of $Q^{2}$ calculates the forecasted validity of a vast and critical framework in partial least square through applying the blindfolding method $[85,86]$. According to Chin [88], "the prediction of observables or potential observables is of much greater relevance than the estimator of what are often artificial construct-parameters" (p. 320). Additionally, the values of $Q^{2}$ for endogenous assumptions were $0.293,0.201,0.308,0.165,0.332$, and 0.333 for experiential value, intention to use, monetary value, recommendation, user experience, and user satisfaction correspondingly, representing an adequate level of forecasted relevance (Table 5). The value of $Q^{2}>0$ exhibited predictive relevance of the model [89], along with showing a moderate impact [76, 88].

Cohen's $f^{2}$ was applied to measure the extent of input of an exogenous construct for $R^{2}$ and to describe the endogenous construct. The measurements of $f^{2}=0.02,0.15$, and 0.35 have denoted as weak, moderate, and strong impact size of the constructs [89]. Particularly, the $f^{2}$ values were enormous (experiential value $\rightarrow$ user experience, $f^{2}=0.841$, over 0.35 ; intention to use $\rightarrow$ user satisfaction, $f^{2}=0.424$, over 0.35 ; monetary value $\rightarrow$ user experience, $f^{2}=0.959$, over 0.35 ; recommendation $\rightarrow$ user satisfaction, $f^{2}=0.370$, over 0.35 ; and user satisfaction $\rightarrow$ monetary value, $f^{2}=0.153$, over 0.35 ), which reflected a huge influence between exogenous constructs and endogenous constructs. A moderate effect between user experience and hedonic features (user experience $\rightarrow$ hedonic features, $f^{2}=0.306$, over 0.15 ) has been revealed. In addition, the values of $f^{2}$ were greater than 0.02 (user experience $\rightarrow$ utilitarian features, $f^{2}=0.066$, over 0.02 ; user satisfaction $\rightarrow$ user experience, $f^{2}=0.054$, over 0.02 ; and user satisfaction $\rightarrow$ experiential value, $f^{2}=0.049$, over 0.02), which mentioned the weak effect size of the constructs.

4.3. Multiple Mediating Effect Tests. A relatively new and renowned analytical technique proposed by different researchers $[76,90]$ has been used to measure user experience's mediating role, experiential value, monetary value, and user satisfaction (H10, H11, H12, H13, H14, and H15). Table 6 illustrates the exogenous variables' indirect and entire effects on the endogenous variables about their mediators. Likewise, the multimediation paths' outcomes, including the measurement of their extent or magnitude of mediation impact, are also shown in Figures 4-6 for an appropriate representation. As stated earlier, the impact of the exogenous variable on the endogenous variables was 
TABLE 2: Scale reliability and measurement.

\begin{tabular}{|c|c|c|c|c|c|c|c|c|}
\hline Constructs & Items & Loading & Mean & SD & Alpha & Rho & $\mathrm{CR}$ & AVE \\
\hline \multirow{3}{*}{ Recommendation } & 1 & 0.863 & 3.371 & 1.051 & & & & \\
\hline & 2 & 0.841 & 3.497 & 1.04 & 0.748 & 0.77 & 0.856 & 0.665 \\
\hline & 3 & 0.736 & 3.323 & 1.059 & & & & \\
\hline \multirow{3}{*}{ Utilitarian features } & 4 & 0.785 & 3.287 & 1.043 & & & & \\
\hline & 5 & 0.823 & 3.361 & 1.121 & 0.75 & 0.751 & 0.857 & 0.666 \\
\hline & 6 & 0.84 & 3.403 & 1.17 & & & & \\
\hline \multirow{3}{*}{ Hedonic features } & 7 & 0.797 & 3.313 & 1.093 & & & & \\
\hline & 8 & 0.782 & 3.416 & 1.182 & 0.745 & 0.788 & 0.849 & 0.653 \\
\hline & 9 & 0.844 & 3.452 & 1.248 & & & & \\
\hline \multirow{3}{*}{ User experience } & 10 & 0.854 & 3.684 & 1.135 & & & & \\
\hline & 11 & 0.836 & 3.435 & 1.113 & 0.724 & 0.739 & 0.845 & 0.646 \\
\hline & 12 & 0.714 & 3.132 & 1.124 & & & & \\
\hline \multirow{3}{*}{ Experiential value } & 13 & 0.853 & 3.226 & 1.159 & & & & \\
\hline & 14 & 0.823 & 3.394 & 1.139 & 0.767 & 0.768 & 0.866 & 0.682 \\
\hline & 15 & 0.801 & 3.216 & 1.066 & & & & \\
\hline \multirow{3}{*}{ Monetary value } & 16 & 0.795 & 3.103 & 1.017 & & & & \\
\hline & 17 & 0.831 & 3.268 & 1.027 & 0.753 & 0.754 & 0.859 & 0.67 \\
\hline & 18 & 0.828 & 3.461 & 1.014 & & & & \\
\hline \multirow{3}{*}{ User satisfaction } & 19 & 0.836 & 3.358 & 0.959 & & & & \\
\hline & 20 & 0.832 & 3.348 & 0.984 & 0.72 & 0.743 & 0.841 & 0.639 \\
\hline & 21 & 0.724 & 3.339 & 1.043 & & & & \\
\hline \multirow{3}{*}{ Intention to use } & 22 & 0.846 & 3.329 & 1.057 & & & & \\
\hline & 23 & 0.846 & 3.413 & 1.04 & 0.802 & 0.808 & 0.883 & 0.716 \\
\hline & 24 & 0.847 & 3.345 & 1.057 & & & & \\
\hline
\end{tabular}

Note: standard deviation, Cronbach's alpha, composite reliability, and average variance are being stated as in the table with the abbreviations of SD, Alpha, CR, and AVE.

TABle 3: Discriminant validity.

\begin{tabular}{|c|c|c|c|c|c|c|c|c|}
\hline & $\mathrm{EV}$ & $\mathrm{HF}$ & INT to use & MV & Recommendation & UE & US & UF \\
\hline Experiential value & 0.826 & & & & & & & \\
\hline Hedonic features & 0.634 & 0.808 & & & & & & \\
\hline Intention to use & 0.405 & 0.496 & 0.846 & & & & & \\
\hline Monetary value & 0.704 & 0.699 & 0.444 & 0.818 & & & & \\
\hline Recommendation & 0.513 & 0.487 & 0.372 & 0.544 & 0.815 & & & \\
\hline User experience & 0.676 & 0.718 & 0.442 & 0.7 & 0.508 & 0.804 & & \\
\hline User satisfaction & 0.652 & 0.606 & 0.546 & 0.711 & 0.52 & 0.653 & 0.799 & \\
\hline Utilitarian features & 0.603 & 0.721 & 0.422 & 0.636 & 0.48 & 0.637 & 0.556 & 0.816 \\
\hline
\end{tabular}

Note: EV stands for experiential value, HF stands for hedonic feature, INT stands for intention, MV stands for monetary value, UE stands for user experience, the US stands for user experience, and UF stands for the utilitarian feature.

significant. Furthermore, the outcomes discovered that the secondary influence of exogenous constructs had been supported significantly. Precisely, user experience mediated the association between hedonic features and experiential value ( $\mathrm{H} 2 \mathrm{a}: b=0.363, p<0.05)$, the correlation between utilitarian features and experiential value (H1a: $b=0.169$, $p<0.05)$, and the connection between utilitarian features and monetary value ( $\mathrm{H} 1 \mathrm{~b}: b=0.175, p<0.05$ ). The experiential value also mediated the association between user experience and user satisfaction (H3a: $b=0.148, p<0.05)$.
While monetary value was a strong mediator between user experience and user satisfaction (H4a: $b=0.278, p<0.05$ ). Also, user satisfaction mediated the correlation between monetary value and recommendation (H5a: $b=0.206$, $p<0.05)$.

4.4. Strength of Mediation. For the magnitude of the mediation, the recommendation of Hair et al. [76] was used to determine to reject and not to reject the mediating hypotheses (H1a, H1b, H2a, H3a, H4a, and H5a). The measurement 
TABLE 4: Structured model.

\begin{tabular}{|c|c|c|c|c|c|}
\hline & Paths & Straight effect & $t$ value & $p$ value & Result \\
\hline $\mathrm{H} 1$ & Hedonic features $\rightarrow$ user experience & 0.537 & 11.16 & 0.001 & Do not reject \\
\hline $\mathrm{H} 2$ & Utilitarian features $\rightarrow$ user experience & 0.25 & 4.816 & 0.001 & Do not reject \\
\hline $\mathrm{H} 3$ & User experience $\rightarrow$ monetary value & 0.7 & 17.889 & 0.001 & Do not reject \\
\hline $\mathrm{H} 4$ & User experience $\rightarrow$ experiential value & 0.676 & 16.259 & 0.001 & Do not reject \\
\hline H5 & User experience $\rightarrow$ user satisfaction & 0.223 & 3.695 & 0.001 & Do not reject \\
\hline H6 & Monetary value $\rightarrow$ user satisfaction & 0.398 & 6.680 & 0.001 & Do not reject \\
\hline $\mathrm{H} 7$ & Experiential value $\rightarrow$ user satisfaction & 0.218 & 3.512 & 0.001 & Do not reject \\
\hline $\mathrm{H} 8$ & User satisfaction $\rightarrow$ intention to use & 0.549 & 10.519 & 0.001 & Do not reject \\
\hline H9 & User satisfaction $\rightarrow$ recommendation & 0.518 & 9.352 & 0.001 & Do not reject \\
\hline
\end{tabular}

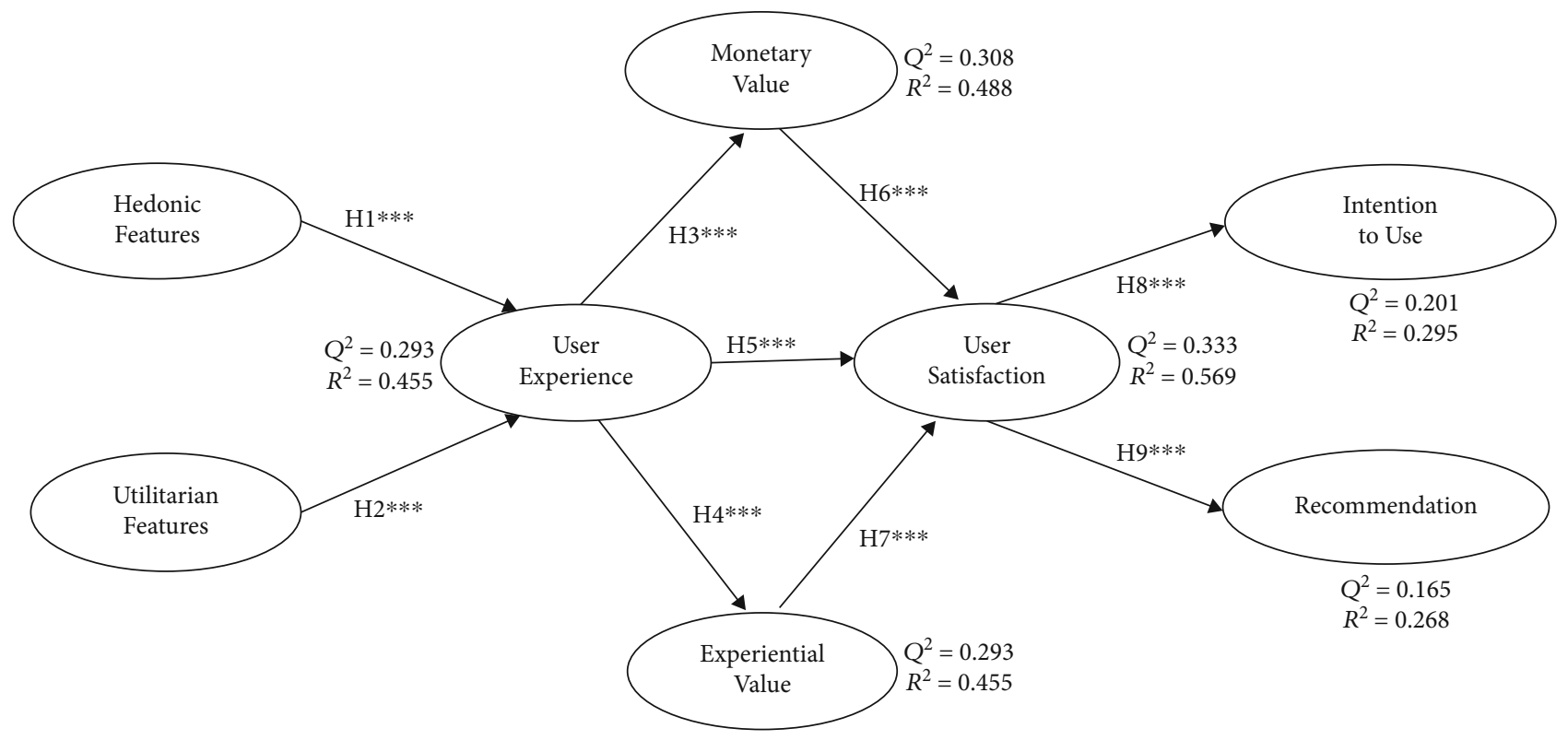

FIGURE 3: Graphical presentation of the structural model.

TABle 5: Effect size and predictive relevance.

\begin{tabular}{lcccc}
\hline $\begin{array}{l}\text { Endogenous } \\
\text { variables }\end{array}$ & $Q^{2}$ & $R^{2}$ & $\begin{array}{c}\text { Exogenous } \\
\text { variables }\end{array}$ & $\begin{array}{c}\text { Effect size } \\
f^{2}\end{array}$ \\
\hline Experiential value & 0.293 & 0.455 & User experience & 0.841 \\
Intention to use & 0.201 & 0.295 & User satisfaction & 0.424 \\
Monetary value & 0.308 & 0.488 & User experience & 0.959 \\
Recommendation & 0.165 & 0.268 & User satisfaction & 0.370 \\
& & & Hedonic features & 0.306 \\
User experience & 0.332 & 0.542 & $\begin{array}{c}\text { Utilitarian } \\
\text { features }\end{array}$ & 0.066 \\
& & & User experience & 0.054 \\
User satisfaction & 0.333 & 0.569 & $\begin{array}{c}\text { Experiential value } \\
\text { Monetary value }\end{array}$ & 0.049 \\
& & & Monet & 0.153 \\
\hline
\end{tabular}

Note: $Q^{2}$ and $R^{2}$ represent predictive relevance as well as coefficient of determination.

of the strength of mediation is essential to give final remarks related to the mediating effect. According to Hair et al. [76], the strengths of mediation were calculated (see Figures 4-6) by using the variance accounted for method $(\mathrm{VAF}<0.2$, no mediation; $0.2 \leq \mathrm{VAF} \leq 0.8$, partial mediation; $\mathrm{VAF}>0.8$, full mediation).

Figure 4 exhibits the degree of mediation regarding the user experience that mediated the association between hedonic and experiential value $(\mathrm{H} 2 \mathrm{a})$ and utilitarian features and experiential value (H1a). The value of VAF was $>0.2$, and henceforth, partial mediation was supported as both direct and indirect effects of hedonic features, and utilitarian features were significant [76].

Figure 5 shows the degree of mediation in the context of experiential value $(\mathrm{H} 3 \mathrm{a})$ and monetary value $(\mathrm{H} 4 \mathrm{a})$ that mediated the correlation between user experience and user satisfaction. The value of VAF was $>0.2$; therefore, partial mediations were supposed since the direct and indirect influence of user experience was positive [76].

Figure 6 illuminated the extent of mediation concerning user experience and mediated the relationship between utilitarian features and monetary value ( $\mathrm{H} 1 \mathrm{~b})$, as well as the relationship between monetary value and recommendation (H5a). The values of VAF were $>0.2$. Thus, partial mediation 
TABLE 6: Multimediation analysis.

\begin{tabular}{|c|c|c|c|c|c|}
\hline & Mediation paths & Specific indirect effect & $t$ values & $p$ values & Remarks \\
\hline $\mathrm{H} 1 \mathrm{a}$ & Utilitarian features $\geq$ user experience $\geq$ experiential value & $0.169^{* * *}$ & 4.412 & 0.001 & Do not reject \\
\hline $\mathrm{H} 1 \mathrm{~b}$ & Utilitarian features $\geq$ user experience $\geq$ monetary value & $0.175^{* * *}$ & 4.51 & 0.001 & Do not reject \\
\hline $\mathrm{H} 2 \mathrm{a}$ & Hedonic features $\geq$ user experience $\geq$ experiential value & $0.363^{* * *}$ & 8.801 & 0.001 & Do not reject \\
\hline $\mathrm{H} 3 \mathrm{a}$ & User experience $\geq$ experiential value $\geq$ user satisfaction & $0.148^{* * *}$ & 3.448 & 0.001 & Do not reject \\
\hline $\mathrm{H} 4 \mathrm{a}$ & User experience $\geq$ monetary value $\geq$ user satisfaction & $0.278^{* * *}$ & 5.687 & 0.001 & Do not reject \\
\hline $\mathrm{H} 5 \mathrm{a}$ & Monetary value $\geq$ user satisfaction $\geq$ recommendation & $0.206 * * *$ & 4.872 & 0.001 & Do not reject \\
\hline
\end{tabular}

Note: we calculated (VAF) recommended by reference [73] to determine to reject or do not reject the mediating effect of hypotheses. As Brockman [73] stated, VAF could be less than 0.2 in the occurrence of significant indirect impact (VAF less than 0.2 , no mediation; $0.2 \leq \mathrm{VAF} \leq 0.8$, partially mediated; VAF greater than 0.8 , full mediation).

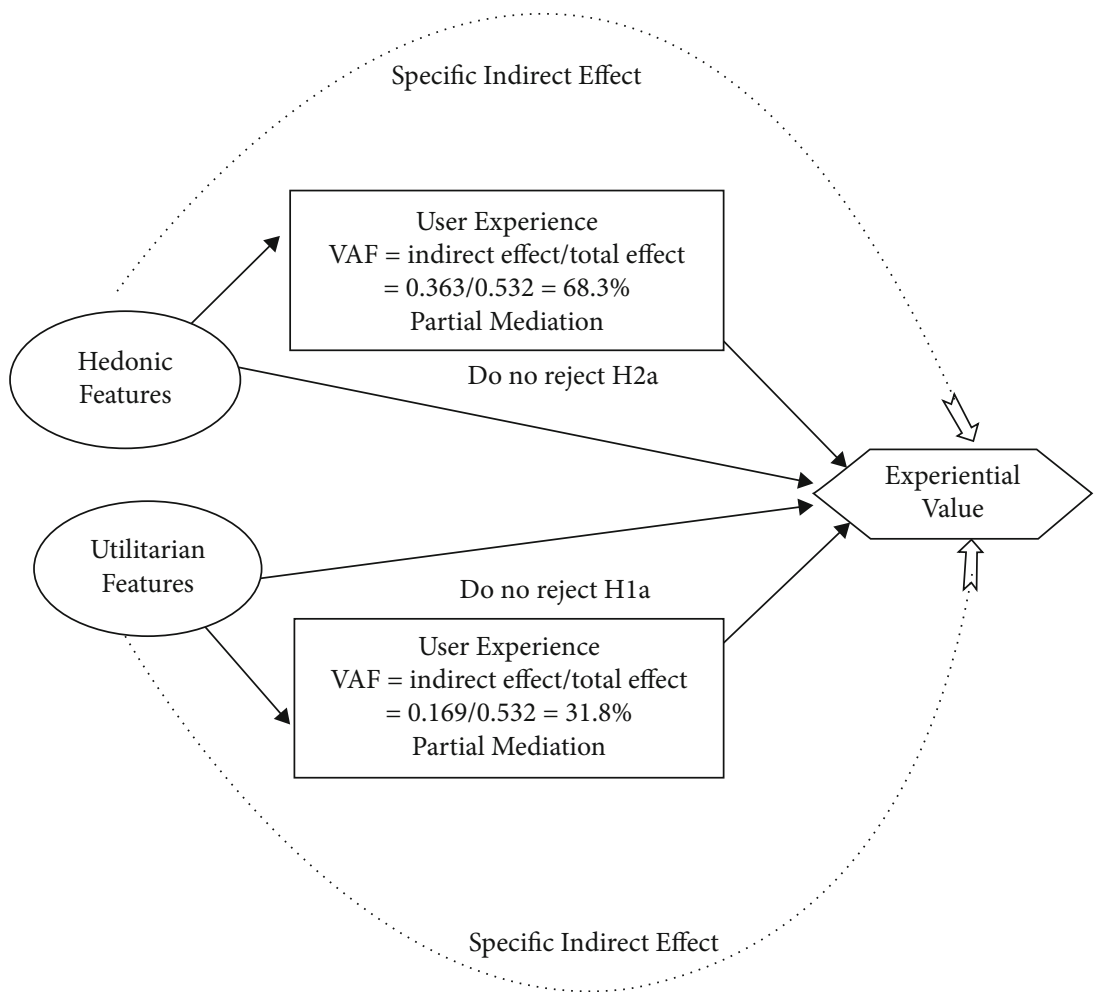

Figure 4: Strength of mediation paths H1a and H2a.

occurred as the direct and indirect impact of utilitarian features, and monetary value was significant [76].

\section{Discussion}

The rapid growth in the online setting has incited enormous development in the number of investigations conducted to measure marketing activities. Though, practically none of any examinations inspect the way gamification increases user experience in the online context. Earlier research acknowledged users experience a reliable indicator of satisfaction $[50,91]$. Till now, limited studies concentrated on users' views about utilitarian and hedonic features as a predictor of user experience [22]. Furthermore, concerning the precursors and results of user experience, it seems that user experience has been identified as a significant forecaster of perceived values (monetary value and experiential) and satisfaction. Hence, it is consequential to distinguish the correlation between the hedonic and utilitarian features, user experience, monetary value, experiential value, satisfaction, and intention to use along with a recommendation in the gamification context.

To achieve the present study's goal, we suggested a comprehensive model (Figure 1) and multimediation models (Figure 2), which consists of 15 proposed hypotheses. The first nine hypotheses measured the direct effect of variables, whereas the remaining hypotheses calculated the mediation effect of six relationships (hedonic features $\geq$ user experience $\geq$ experiential value, utilitarian features $\geq$ user experience $\geq$ experiential value, user experience $\geq$ experiential value $\geq$ user satisfaction, user experience $\geq$ monetary value $\geq$ user satisfaction, utilitarian features $\geq$ user experience $\geq$ monetary 


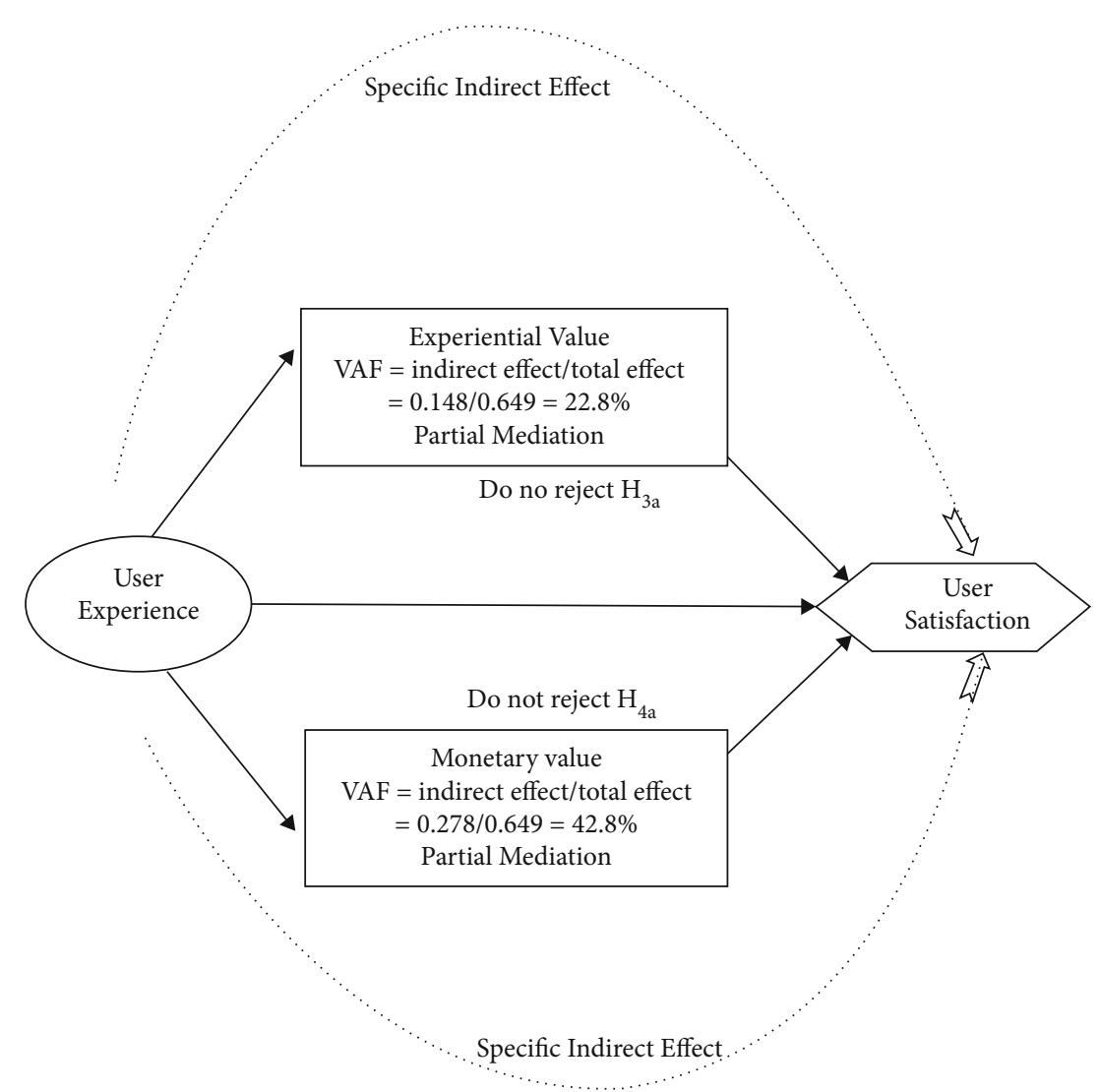

FIGURE 5: Strength mediation paths H3a and H4a.

value, monetary value $\geq$ user satisfaction $\geq$ recommendation). The findings demonstrated a strong significance between the constructs of $\mathrm{H} 1$ (hedonic features $\rightarrow$ user experience) and $\mathrm{H} 2$ (utilitarian features $\rightarrow$ user experience), which confirms that both hypotheses were proven. These findings are parallel to the outcomes of prior studies [22, $24,27]$. According to the research conducted by [24, 27], hedonic and utilitarian features of a website enhance customer motivation to use and generate a greater user experience, which proves that both of these websites feature strongly influence the different aspects of user experience.

Similarly, our findings were also parallel to the notion of [22] that hedonic and utilitarian features have a substantial effect on user experience, particularly in the context of gamification of websites. Hedonic features of a website in terms of design, content, and product/service pictorial representation create an appeal that further affects the user experience of shopping towards that website [25]. Similarly, the results of $\mathrm{H} 3$ (user experience $\rightarrow$ monetary value) and H4 (user experience $\rightarrow$ experiential value) reported a significant positive relationship, which means that user experience strongly affects monetary value and experiential value. These findings are also similar to past studies [92-94]. Value is the prerequisite of product and service assessment. It also reflects the overall relationship between customer and firm, so there is a need to create a holistic and good user experience, ensuring that value delivers to both parties [92]. From the monetary value perspective, a good and multilevel user experience can be achieved when less is paid for products and services [95]. As proposed by reference [22], user experience can be directly affected by experiential value based on happiness and a sense of fulfillment achieved by using a gamification site. Existing literature likewise revealed the substantial existence of experiential value in the whole process of value, mainly in service marketing [39].

Furthermore, as per findings of the H5 (user experience $\rightarrow$ user satisfaction),H6 (monetary value $\rightarrow$ user satisfaction), and H7 (experiential value $\rightarrow$ user satisfaction), it has revealed that user experience, monetary value, and the experiential value were positively related to user satisfaction. Correspondingly, these results are consistent with the findings of previous literature. Srivastava and Kaul [50] found user experience has a significant influence on user satisfaction. The authors further argued that the user's experience in the retail industry can be an important dimension of service and might directly influence user satisfaction. Consistently, [88] documented that user experience of leisure shopping directly affects user satisfaction. Besides, reference $[96,97]$ suggested that user online shopping experiential value affirmatively impacts user satisfaction. Moreover, Shieh et al. [98] verified a consumer behavior framework of online gamers and found that experiential value directly relates to satisfaction. According to the reference, users with increase experiential value can achieve positive satisfaction.

The result of H6 is supported by the study of [99], which demonstrated that online consumers are in quest of better 


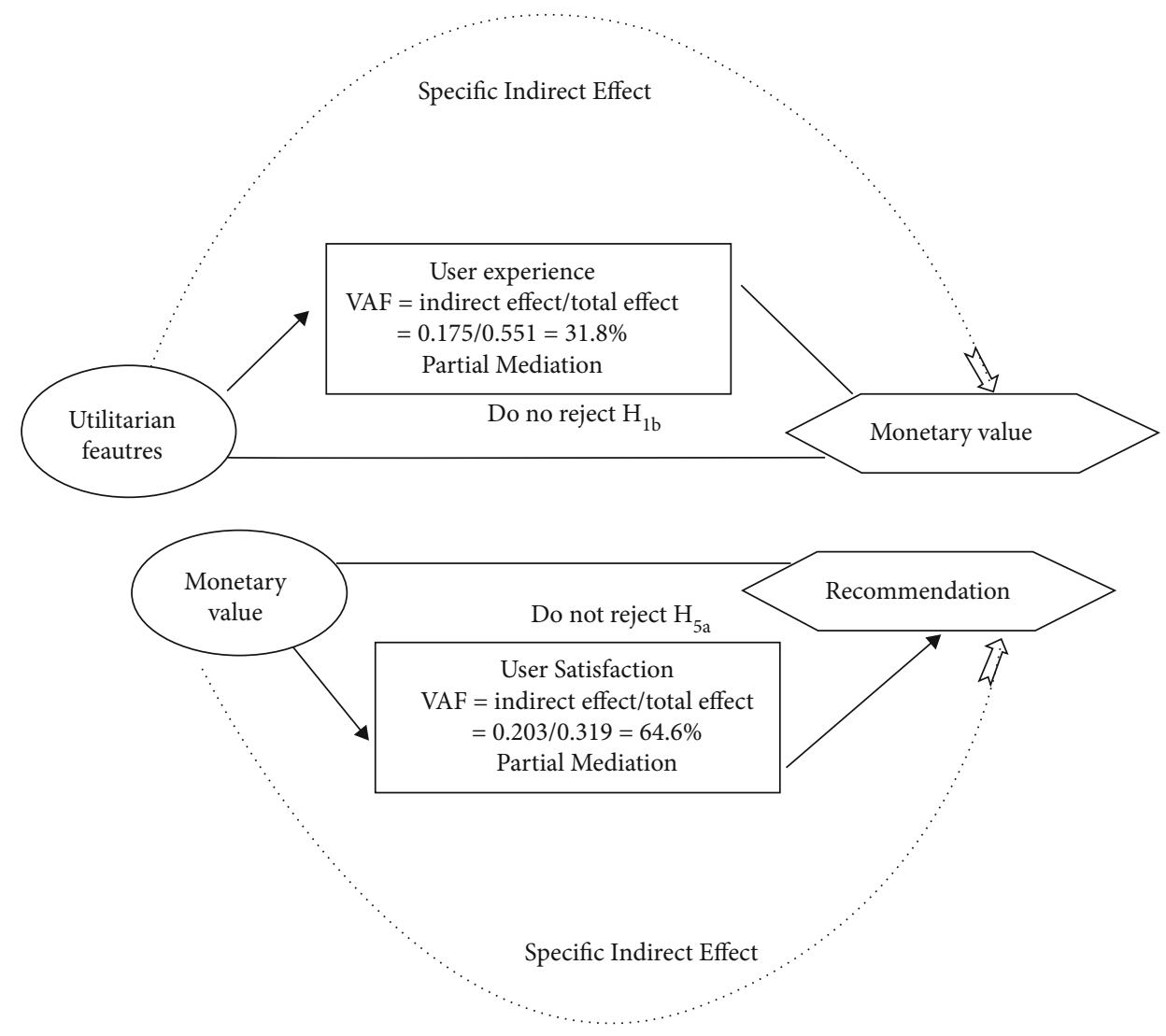

Figure 6: Strength mediation paths H1b and H5a.

monetary value products/services through which they can achieve the desired level of satisfaction. Users tend to be highly satisfied when they acquire economical prices for the products and services through website shopping [100]. The investigation of reference $[101,102]$ reported that finding good deals and discounts on specific products and services positively influence user satisfaction in achieving a personal achievement. The findings of $\mathrm{H} 8$ (user satisfaction $\rightarrow$ intention to use) and $\mathrm{H} 9$ (user satisfaction $\rightarrow$ recommendation) reported a positive influence of user satisfaction on intention to use and recommendation of the gamification website. Hence, these findings reinforced the results of $[61,62,103]$, which narrates that satisfied users are willing to recommend the services to their friends and peers.

Similarly, reference $[66,104]$ revealed that satisfactory tourists would have a firm intention to use and recommend those services to others, which seems to be a significant behavioral outcome. Belanche et al. [61] documented that satisfied consumers show a superior intention to use the company's products and services. User satisfaction has a direct impact on intention to use toward online shopping [105]. Another key objective of this study is to measure the mediating effect among different constructs of the proposed research model, which is the novel contribution in the existing literature because the mediation of $\mathrm{H} 1 \mathrm{a}, \mathrm{H} 1 \mathrm{~b}, \mathrm{H} 2 \mathrm{a}, \mathrm{H} 3 \mathrm{a}$, $\mathrm{H} 4 \mathrm{a}$, and $\mathrm{H} 5 \mathrm{a}$ because no prior study has used these relationships and measure their mediation effect in the context of gamification website. Based on the findings of multimedia- tion analysis, it concluded that user experience partially mediates the relation between hedonic features and experiential value and utilitarian features and experiential value ( $\mathrm{H} 1 \mathrm{a}$ and $\mathrm{H} 2 \mathrm{a}$ ). It further showed that to some extent, consumer experience regarding the use of the gamification website is based on their utilitarian and hedonic features, which create an appeal, fun, accomplish functional needs, and ultimately lead to a memorable experience.

The result of the mediation suggested that experiential value and monetary value, to some extent, mediate the paths between user experience and user satisfaction ( $\mathrm{H} 3 \mathrm{a}$ and $\mathrm{H} 4 \mathrm{a})$. Moreover, the direct effect of these constructs was significant, which means experiential value and monetary value have a vital contribution to developing a good user experience and, at the same time, ensuring the satisfaction of using the gamification website.

Besides, user experience was considered a partial mediator between utilitarian features and monetary value (H1b), whereas user satisfaction somehow mediates the association between monetary value and recommendation ( $\mathrm{H} 5 \mathrm{a})$. These effects revealed that such constructs could improve the overall mechanism of websites in the online gamification perspective.

\section{Implications}

Our research presents some useful theoretical insights in the literature. First, we document the critical contribution of user 
experience in the milieu of gamification. A user experience is an important variable and essential for the diffusion of a gamification perspective. Still, research in the context of the website's gamification is insufficient regarding the relationship between user experience and satisfaction. Hence, this paper is the novel attempt to measure the effect of hedonic features and utilitarian features on user experience and investigate to what extent user experience influences user satisfaction of using the gamification website. More importantly, to mitigate the complexity of user experience, we measured its direct effect and used a multimediation approach to investigate the mediating role of user experience on several other constructs of the proposed research model. On a managerial level, gamification techniques have been recognized as a unique marketing tool to be used to increase user experience and satisfaction. In a rapidly competitive environment, the acquisition of user satisfaction is a crucial issue for marketers [106-109]. Thus, the novel use of gamification applications can help organizations and online retailers enhance product attributes, which deliver a memorable user experience, results in satisfaction, and recommendation of product/service. In addition, business managers must realize the significance of experiential value and monetary value, which are the vital building blocks for enhancing user experience and satisfaction. So when designing the websites, the need is to make sure that the attributes (hedonic features and utilitarian features) should be aligned with users' perceptions, which therefore improve user behavioral intention to buy from such websites. This contention is also parallel to the existing literature that the website's unique interface empowers an organization to produce a constructive user experience $[18,110]$.

To sum up, the findings suggest that the essential component of any business's assessment is user experience and satisfaction that further central to intention to use and recommendation of the product/service. Each user experience can be positive if/provided website managers can use a comprehensive strategy for website design such as features and perceived value. As the findings also confirm a vital mediating role of the proposed constructs in influencing the user's perception about gamification websites, which previous studies failed to investigate. Consequently, these results describe noteworthy implications in the field of gamification of website and user experience.

\section{Conclusion, Limitation, and Future Research}

The growing importance of gamification techniques has set a new trend of running a business in an online environment. This unique online shopping trend has urged marketers to consider their website design and features, providing a tremendous user experience and being acknowledged by business success. Therefore, this research presented a multimediation model of website features, perceived value, user experience, user satisfaction, and actual behavioral outcomes to measure the influence of gamified website and overall user behavior. The results conclude that gamification has a substantial impact on user intention to buy online. Gamification is a beneficial approach for websites to use to encourage user's experience and satisfaction, thus increasing the recom- mendation of using the website to potential customers. The findings confirm that game elements in websites provide many benefits, particularly concerning web features, user experience, perceived value, and user satisfaction. All of the proposed constructs have a vital significance on the intention to use and recommendation of using gamified websites. The results proved that gamification is a potential marketing tool in the online business environment, which can provide a memorable shopping experience to end-users.

The multimediation analysis of the proposed hypotheses reported effect a partial impact on overall user behavior. Conclusively, this study found the effectiveness of gamification applications on online shopping to achieve anticipated user behavior. Firms likewise need to design their websites to satisfy both ends (retailers and end-users) and motivate business experts to use gamified business applications.

The study contains some limitations which can also provide directions to future researchers. First, the findings' generalizability limits the applicability of results as the current study conduct analysis in the context of an online food website (http://www.foodpanda.com.pk). Future studies can analyze from a different perspective, such as e-learning and e-banking. Second, this study used a three-level multimediation approach; future research can be based on advancedlevel multimodule mediation to verify its effect in the same context. Third, since user experience is a multidimensional construct, future research could extend the present model based on user experience, user satisfaction, and convenience metrics. Four, future researchers can also consider the user characteristics, which might moderate the effect of user experience in the same context.

\section{Data Availability}

Data will be provided on request.

\section{Conflicts of Interest}

All authors have no conflict of the statement.

\section{Acknowledgments}

This project is supported by Sichuan Wine Development Research Center (CJZB18-02), Sichuan Circular Economy Research Center (XHJJ-1815), and the Humanity and Social Science Youth foundation of Ministry of Education of China (19YJC630060, 19YJC860033, and 20YJC860006).

\section{References}

[1] A. Bilgihan, J. Kandampully, and T. Zhang, "Towards a unified customer experience in online shopping environments," International Journal of Quality and Service Sciences, vol. 8, no. 1, pp. 102-119, 2016.

[2] S. Rose, M. Clark, P. Samouel, and N. Hair, "Online customer experience in e-retailing: an empirical model of antecedents and outcomes," Journal of Retailing, vol. 88, no. 2, pp. 308$322,2012$. 
[3] M. Naqvi, S. Li, Y. Jiang, and M. H. A. Naqvi, "The rise of social networking sites," Asia Pacific Journal of Marketing and Logistics, vol. 32, no. 1, pp. 232-252, 2019.

[4] K. Robson, K. Plangger, J. Kietzmann, I. McCarthy, and L. Pitt, Understanding Gamification of Consumer Experiences, ACR North American Advances, 2014.

[5] J. Yushi, M. H. A. Naqvi, and M. H. Naqvi, "Using social influence processes and psychological factors to measure pervasive adoption of social networking sites: evidence from Pakistan," Emerging Markets Finance and Trade, vol. 54, no. 15, pp. 3485-3499, 2018.

[6] K. Robson, K. Plangger, J. H. Kietzmann, I. McCarthy, and L. Pitt, "Game on: engaging customers and employees through gamification," Business Horizons, vol. 59, no. 1, pp. 29-36, 2016.

[7] G. Zichermann and J. Linder, Game-Based Marketing: Inspire Customer Loyalty through Rewards, Challenges, and Contests, John Wiley \& Sons, 2010.

[8] T. Leclercq, W. Hammedi, and I. Poncin, "The boundaries of gamification for engaging customers: effects of losing a contest in online co-creation communities," Journal of Interactive Marketing, vol. 44, pp. 82-101, 2018.

[9] V. Insley and D. Nunan, "Gamification and the online retail experience," International Journal of Retail \& Distribution Management, vol. 42, no. 5, pp. 340-351, 2014.

[10] M. Sigala, "The application and impact of gamification funware on trip planning and experiences: the case of TripAdvisor's funware," Electronic Markets, vol. 25, no. 3, pp. 189-209, 2015.

[11] K. Huotari and J. Hamari, "A definition for gamification: anchoring gamification in the service marketing literature," Electronic Markets, vol. 27, no. 1, pp. 21-31, 2017.

[12] L. De-Marcos, A. Domínguez, J. Saenz-de-Navarrete, and C. Pagés, "An empirical study comparing gamification and social networking on e-learning," Computers \& Education, vol. 75, pp. 82-91, 2014.

[13] S. Deterding, R. Khaled, L. E. Nacke, and D. Dixon, "Gamification: toward a definition," in CHI 2011 Gamification Workshop Proceedings, vol. 12, Vancouver BC, Canada, May 2011.

[14] K. Huotari and J. Hamari, "Defining gamification: a service marketing perspective," in AcademicMindTrek '12: International Conference on Media of the Future, pp. 17-22, Tampere Finland, October 2012.

[15] B. Burke, Gamification 2020: What is the Future of Gamification?, Gartner. Inc, 2012.

[16] R. K. Mishra, Infosys labs briefings gamification: rediscover the power of engagement, vol. 11, no. 3, 2013Infosys Labs Briefings, 2013.

[17] K. Seaborn and D. I. Fels, "Gamification in theory and action: a survey," International Journal of Human-Computer Studies, vol. 74, pp. 14-31, 2015.

[18] N. Xi and J. Hamari, "Does gamification satisfy needs? A study on the relationship between gamification features and intrinsic need satisfaction," International Journal of Information Management, vol. 46, pp. 210-221, 2019.

[19] Y. Yang, Y. Asaad, and Y. Dwivedi, "Examining the impact of gamification on intention of engagement and brand attitude in the marketing context," Computers in Human Behavior, vol. 73, pp. 459-469, 2017.

[20] G. Baptista and T. Oliveira, "Why so serious? Gamification impact in the acceptance of mobile banking services," Internet Research, vol. 27, no. 1, pp. 118-139, 2017.
[21] J. Hamari and J. Koivisto, "Why do people use gamification services?," International Journal of Information Management, vol. 35, no. 4, pp. 419-431, 2015.

[22] C. L. Hsu, Y. C. Chen, T. N. Yang, and W. K. Lin, "Do website features matter in an online gamification context? Focusing on the mediating roles of user experience and attitude," Telematics and Informatics, vol. 34, no. 4, pp. 196-205, 2017.

[23] E. Fischer and S. J. Arnold, "More than a labor of love: gender roles and Christmas gift shopping," Journal of Consumer Research, vol. 17, no. 3, pp. 333-345, 1990.

[24] H. L. O'Brien, "The influence of hedonic and utilitarian motivations on user engagement: the case of online shopping experiences," Interacting with Computers, vol. 22, no. 5, pp. 344-352, 2010.

[25] C. M. Chiu, E. T. Wang, Y. H. Fang, and H. Y. Huang, "Understanding customers' repeat purchase intentions in B2C e-commerce: the roles of utilitarian value, hedonic value and perceived risk," Information Systems Journal, vol. 24, no. 1, pp. 85-114, 2014.

[26] B. J. Babin, W. R. Darden, and M. Griffin, "Work and/or fun: measuring hedonic and utilitarian shopping value," Journal of Consumer Research, vol. 20, no. 4, pp. 644-656, 1994.

[27] A. Bilgihan and M. Bujisic, "The effect of website features in online relationship marketing: a case of online hotel booking," Electronic Commerce Research and Applications, vol. 14, no. 4, pp. 222-232, 2015.

[28] M. L. Sheng and T. S. Teo, "Product attributes and brand equity in the mobile domain: the mediating role of customer experience," International Journal of Information Management, vol. 32, no. 2, pp. 139-146, 2012.

[29] Pine BJ 2nd and J. H. Gilmore, "Welcome to the experience economy," Harvard Business Review, vol. 76, no. 4, pp. 97105, 1998.

[30] D. LaSalle and T. A. Britton, Priceless: Turning Ordinary Products into Extraordinary Experiences, Harvard Business School Press, Boston, MA, 2003.

[31] C. Shaw and J. Ivens, Building Great User Experiences, Mac Millan, New York, 2005.

[32] C. K. Prahalad and V. Ramaswamy, "Co-creation experiences: the next practice in value creation," Journal of Interactive Marketing, vol. 18, no. 3, pp. 5-14, 2004.

[33] P. C. Verhoef, K. N. Lemon, A. Parasuraman, A. Roggeveen, M. Tsiros, and L. A. Schlesinger, "Customer experience creation: determinants, dynamics and management strategies," Journal of Retailing, vol. 85, no. 1, pp. 31-41, 2009.

[34] X. Hu, Q. Huang, X. Zhong, R. M. Davison, and D. Zhao, "The influence of peer characteristics and technical features of a social shopping website on a consumer's purchase intention," International Journal of Information Management, vol. 36, no. 6, pp. 1218-1230, 2016.

[35] A. Bilgihan, F. Okumus, K. Nusair, and M. Bujisic, "Online experiences: flow theory, measuring online customer experience in e-commerce and managerial implications for the lodging industry," Information Technology \& Tourism, vol. 14, no. 1, pp. 49-71, 2014.

[36] C. Gan and W. Wang, "The influence of perceived value on purchase intention in social commerce context," Internet Research, vol. 27, no. 4, pp. 772-785, 2017.

[37] C. L. Hsu and J. C. C. Lin, "Effect of perceived value and social influences on mobile app stickiness and in-app purchase 
intention," Technological Forecasting and Social Change, vol. 108, pp. 42-53, 2016.

[38] V. A. Zeithaml, "Consumer perceptions of price, quality, and value: a means-end model and synthesis of evidence," The Journal of Marketing, vol. 52, no. 3, pp. 2-22, 1988.

[39] M. R. Lee, D. C. Yen, and C. Y. Hsiao, "Understanding the perceived community value of Facebook users," Computers in Human Behavior, vol. 35, pp. 350-358, 2014.

[40] J. Gummerus, "Value creation processes and value outcomes in marketing theory," Marketing Theory, vol. 13, no. 1, pp. 19-46, 2013.

[41] J. C. Sweeney and G. N. Soutar, "Consumer perceived value: the development of a multiple item scale," Journal of Retailing, vol. 77, no. 2, pp. 203-220, 2001.

[42] A. A. Mohd-Any, H. Winklhofer, and C. Ennew, "Measuring users' value experience on a travel website (e-value) what value is cocreated by the user?," Journal of Travel Research, vol. 54, no. 4, pp. 496-510, 2015.

[43] L. Y. Wu, K. Y. Chen, P. Y. Chen, and S. L. Cheng, "Perceived value, transaction cost, and repurchase-intention in online shopping: a relational exchange perspective," Journal of Business Research, vol. 67, no. 1, pp. 2768-2776, 2014.

[44] D. J. Kim, W. G. Kim, and J. S. Han, "A perceptual mapping of online travel agencies and preference attributes," Tourism Management, vol. 28, no. 2, pp. 591-603, 2007.

[45] C. Gentile, N. Spiller, and G. Noci, "How to sustain the customer experience: an overview of experience components that co-create value with the customer," European Management Journal, vol. 25, no. 5, pp. 395-410, 2007.

[46] Y. F. Kuo, C. M. Wu, and W. J. Deng, "The relationships among service quality, perceived value, customer satisfaction, and post-purchase intention in mobile value-added services," Computers in Human Behavior, vol. 25, no. 4, pp. 887-896, 2009.

[47] J. R. Carlson and R. W. Zmud, "Channel expansion theory: a dynamic view of medial and information richness perceptions," Academy of management proceedings, , no. 1,, pp. 280-284, academy of management, Briarcliff manor, NY 10510, 1994.

[48] R. L. Oliver, Varieties of Value in the Consumption Satisfaction Response, ACR North American Advances, 1996.

[49] L. Murphy, G. Moscardo, P. Benckendorff, and P. Pearce, "Evaluating tourist satisfaction with the retail experience in a typical tourist shopping village," Journal of Retailing and Consumer Services, vol. 18, no. 4, pp. 302-310, 2011.

[50] M. Srivastava and D. Kaul, "Social interaction, convenience and customer satisfaction: the mediating effect of customer experience," Journal of Retailing and Consumer Services, vol. 21, no. 6, pp. 1028-1037, 2014.

[51] M. Limayem and C. M. Cheung, "Predicting the continued use of Internet-based learning technologies: the role of habit," Behaviour \& Information Technology, vol. 30, no. 1, pp. 9199, 2011.

[52] K. C. Ling, L. T. Chai, and T. H. Piew, "The effects of shopping orientations, online trust and prior online purchase experience toward customers' online purchase intention," International Business Research, vol. 3, no. 3, 2010.

[53] A. Bhattacherjee, "An empirical analysis of the antecedents of electronic commerce service continuance," Decision Support Systems, vol. 32, no. 2, pp. 201-214, 2001.
[54] C. M. Chiu, M. H. Hsu, H. Lai, and C. M. Chang, "Re-examining the influence of trust on online repeat purchase intention: the moderating role of habit and its antecedents," Decision Support Systems, vol. 53, no. 4, pp. 835-845, 2012.

[55] M. H. Hsu, C. M. Chang, and L. W. Chuang, "Understanding the determinants of online repeat purchase intention and moderating role of habit: the case of online group-buying in Taiwan," International Journal of Information Management, vol. 35, no. 1, pp. 45-56, 2015.

[56] W.-Y. Tsao, "The fitness of product information: evidence from online recommendations," International Journal of Information Management, vol. 33, no. 1, pp. 1-9, 2013.

[57] A. L. Ostrom, A. Parasuraman, D. E. Bowen, L. Patrício, and C. A. Voss, "Service research priorities in a rapidly changing context," Journal of Service Research, vol. 18, no. 2, pp. 127159, 2015.

[58] A. O'Cass and L. V. Ngo, "Examining the firm's value creation process: a managerial perspective of the firm's value offering strategy and performance," British Journal of Management, vol. 22, no. 4, pp. 646-671, 2011.

[59] J. J. Cronin Jr., M. K. Brady, and G. T. M. Hult, "Assessing the effects of quality, value, and customer satisfaction on consumer behavioral intentions in service environments," Journal of Retailing, vol. 76, no. 2, pp. 193-218, 2000.

[60] H. Lempinen and R. Rajala, "Exploring multi-actor value creation in IT service processes," Journal of Information Technology, vol. 29, no. 2, pp. 170-185, 2014.

[61] D. Belanche, L. V. Casaló, and M. Guinalíu, "Website usability, consumer satisfaction and the intention to use a website: the moderating effect of perceived risk," Journal of Retailing and Consumer Services, vol. 19, no. 1, pp. 124-132, 2012.

[62] S. Hosany, G. Prayag, R. van der Veen, S. Huang, and S. Deesilatham, "Mediating effects of place attachment and satisfaction on the relationship between tourists' emotions and intention to recommend," Journal of Travel Research, vol. 56, no. 8, pp. 1079-1093, 2016.

[63] C. Agustin and J. Singh, "Curvilinear effects of consumer loyalty determinants in relational exchanges," Journal of Marketing Research, vol. 42, no. 1, pp. 96-108, 2005.

[64] G. L. Bradley and B. A. Sparks, "Antecedents and consequences of consumer value," Journal of Travel Research, vol. 51, no. 2, pp. 191-204, 2011.

[65] A. Montanari, R. Restrepo, and P. Tetali, "Reconstruction and clustering in random constraint satisfaction problems," SIAM Journal on Discrete Mathematics, vol. 25, no. 2, pp. 771-808, 2011.

[66] G. Prayag and C. Ryan, "Antecedents of tourists' loyalty to Mauritius," Journal of Travel Research, vol. 51, no. 3, pp. 342-356, 2011.

[67] C. Xu, D. Peak, and V. Prybutok, "A customer value, satisfaction, and loyalty perspective of mobile application recommendations," Decision Support Systems, vol. 79, pp. 171183, 2015.

[68] A. Rychalski and S. Hudson, "Asymmetric effects of customer emotions on satisfaction and loyalty in a utilitarian service context," Journal of Business Research, vol. 71, pp. 84-91, 2017.

[69] X. L. Jin, M. K. Lee, and C. M. Cheung, "Predicting continuance in online communities: model development and empirical test," Behaviour \& Information Technology, vol. 29, no. 4, pp. 383-394, 2010. 
[70] A. C. Burns and R. F. Bush, "Developing questions and designing the questionnaire," Marketing Research, pp. 228361, 2009.

[71] C. Mathwick, N. K. Malhotra, and E. Rigdon, "The effect of dynamic retail experiences on experiential perceptions of value: an internet and catalog comparison," Journal of Retailing, vol. 78, no. 1, pp. 51-60, 2002.

[72] C. Gentile, N. Spiller, and G. Noci, "How to sustain the customer experience:," European Management Journal, vol. 25, no. 5, pp. 395-410, 2007.

[73] B. K. Brockman, "The influence of affective state on satisfaction ratings," American Marketing Association. Conference Proceedings, , American marketing association., 1998.

[74] D. E. Severt, The customer's Path to Loyalty:Justice, and Customer Satisfaction A Partial Test of the Relationships of Prior Experience, [Ph.D thesis]Virginia Tech, 2002.

[75] Y. K. Lee, C. K. Lee, S. K. Lee, and B. J. Babin, "Festivalscapes and patrons' emotions, satisfaction, and loyalty," Journal of Business Research, vol. 61, no. 1, pp. 56-64, 2008.

[76] J. F. Hair Jr., M. Sarstedt, C. M. Ringle, and S. P. Gudergan, Advanced Issues in Partial Least Squares Structural Equation Modeling, Sage Publications, 2017.

[77] University of Groningen, T. K. Dijkstra, J. Henseler, University of Twente, and Universidade Nova de Lisboa, "Consistent partial least squares path modeling," MIS Quarterly, vol. 39, no. 2, pp. 297-316, 2015.

[78] A. M. Gadermann, M. Guhn, and B. D. Zumbo, "Estimating ordinal reliability for Likert-type and ordinal item response data: a conceptual, empirical, and practical guide," Practical Assessment, Research \& Evaluation, vol. 17, no. 3, 2012.

[79] W. W. Chin, "How to write up and report PLS analyses," in Handbook of Partial Least Squares, In Handbook of partial least squares (pp. 655-690), pp. 655-690, Springer, Berlin, Heidelberg, 2010.

[80] J. F. Hair, C. M. Ringle, and M. Sarstedt, "PLS-SEM: indeed a silver bullet," Journal of Marketing Theory and Practice, vol. 19, no. 2, pp. 139-152, 2011.

[81] F. Schuberth, J. Henseler, and T. K. Dijkstra, "Partial least squares path modeling using ordinal categorical indicators," Quality \& Quantity, vol. 52, no. 1, pp. 9-35, 2018.

[82] R. B. Kline, Principles and Practice of Structural Equation Modeling, Guilford publications, 2015.

[83] C. Fornell and D. F. Larcker, "Evaluating structural equation models with unobservable variables and measurement error," Journal of Marketing Research, vol. 18, no. 1, pp. 39-50, 1981.

[84] J. Henseler, C. M. Ringle, and M. Sarstedt, "Testing measurement invariance of composites using partial least squares," International Marketing Review, vol. 33, no. 3, pp. 405-431, 2016.

[85] L. T. Hu and P. M. Bentler, "Cutoff criteria for fit indexes in covariance structure analysis: conventional criteria versus new alternatives," Structural Equation Modeling: A Multidisciplinary Journal, vol. 6, no. 1, pp. 1-55, 1999.

[86] D. A. Kenny, "Measuring model fit in structural equation modeling," 2014, January 2019, https://www.davidak-enny .net $/ \mathrm{cm} /$ fit.htm.

[87] M. Tenenhaus, V. E. Vinzi, Y. M. Chatelin, and C. Lauro, "PLS path modeling," Computational Statistics \& Data Analysis, vol. 48, no. 1, pp. 159-205, 2005.
[88] W. W. Chin, "The partial least squares approach to structural equation modeling," Modern Methods for Business Research, vol. 295, no. 2, pp. 295-336, 1998.

[89] J. Cohen, “The T Test for Means," Statistical power analysis for the behavioural sciences, 1988.

[90] G. C. Carrión, C. Nitzl, and J. L. Roldán, “Mediation analyses in partial least squares structural equation modeling: guidelines and empirical examples," in Partial Least Squares Path Modeling, pp. 173-195, Springer, Cham, 2017.

[91] A. Poushneh and A. Z. Vasquez-Parraga, "Discernible impact of augmented reality on retail customer's experience, satisfaction and willingness to buy," Journal of Retailing and Consumer Services, vol. 34, pp. 229-234, 2017.

[92] J. C. Hong, P. H. Lin, and P. C. Hsieh, "The effect of consumer innovativeness on perceived value and continuance intention to use smartwatch," in Computers in Human Behavior, Vol. 67, pp. 264-272, Elsevier, 2017.

[93] A. Kazeminia, M. Hultman, and R. Mostaghel, "Why pay more for sustainable services? The case of ecotourism," Journal of Business Research, vol. 69, no. 11, pp. 4992-4997, 2016.

[94] J. Marbach, C. R. Lages, and D. Nunan, "Who are you and what do you value? Investigating the role of personality traits and customer-perceived value in online customer engagement," Journal of Marketing Management, vol. 32, no. 5-6, pp. 502-525, 2016.

[95] M. I. El-Adly and R. Eid, "Measuring the perceived value of malls in a non-Western context: the case of the UAE," International Journal of Retail \& Distribution Management, vol. 43, no. 9, pp. 849-869, 2015.

[96] C. S. Lee and S. B. Bang, "The effects of shopping value on online purchasing intention: focus on product attribute importance as intervening variables," Korean Marketing Research, vol. 19, no. 2, pp. 41-69, 2004.

[97] T. Verhagen, F. Feldberg, B. van den Hooff, S. Meents, and J. Merikivi, "Satisfaction with virtual worlds: an integrated model of experiential value," Information \& Management, vol. 48, no. 6, pp. 201-207, 2011.

[98] K. F. Shieh and M. S. Cheng, "An empirical study of experiential value and lifestyles and their effects on satisfaction in adolescents: an example using online gaming," Adolescence, vol. 42, no. 165, 2007.

[99] X. Chen, S. Goodman, J. Bruwer, and J. Cohen, "Beyond better wine: the impact of experiential and monetary value on wine tourists' loyalty intentions," Asia Pacific Journal of Tourism Research, vol. 21, no. 2, pp. 172-192, 2016.

[100] F. J. Martínez-López, C. Pla-García, J. C. Gázquez-Abad, and I. Rodríguez-Ardura, "Utilitarian motivations in online consumption: dimensional structure and scales," Electronic Commerce Research and Applications, vol. 13, no. 3, pp. 188-204, 2014.

[101] M. J. Arnold and K. E. Reynolds, "Hedonic shopping motivations," Journal of Retailing, vol. 79, no. 2, pp. 77-95, 2003.

[102] P. L. To, C. Liao, and T. H. Lin, "Shopping motivations on Internet: a study based on utilitarian and hedonic value," Technovation, vol. 27, no. 12, pp. 774-787, 2007.

[103] N. Bontis, L. D. Booker, and A. Serenko, "The mediating effect of organizational reputation on customer loyalty and service recommendation in the banking industry," Management Decision, vol. 45, no. 9, pp. 1426-1445, 2007.

[104] S. Grappi and F. Montanari, "The role of social identification and hedonism in affecting tourist re-patronizing behaviours: 
the case of an Italian festival," Tourism Management, vol. 32, no. 5, pp. 1128-1140, 2011.

[105] L. Wu, "The antecedents of customer satisfaction and its link to complaint intentions in online shopping: an integration of justice, technology, and trust," International Journal of Information Management, vol. 33, no. 1, pp. 166-176, 2013.

[106] M. H. A. Naqvi, Y. Jiang, M. Miao, and M. H. Naqvi, “The effect of social influence, trust, and entertainment value on social media use: evidence from Pakistan," Cogent Business \& Management, vol. 7, no. 1, article 1723825, 2020.

[107] Y. Jiang, M. H. Naqvi, and M. H. Abbas Naqvi, "Psychological predictors of Facebook use: a literature review," International Journal of Management, Economics and Social Sciences, vol. 9, no. 2, pp. 113-130, 2020.

[108] N. Xi and J. Hamari, "Does gamification affect brand engagement and equity? A study in online brand communities," Journal of Business Research, vol. 109, pp. 449-460, 2020.

[109] B. Yang, Y. Liu, Y. Liang, and M. Tang, "Exploiting user experience from online customer reviews for product design," International Journal of Information Management, vol. 46, pp. 173-186, 2019.

[110] X. Zheng, J. Men, F. Yang, and X. Gong, "Understanding impulse buying in mobile commerce: an investigation into hedonic and utilitarian browsing," International Journal of Information Management, vol. 48, pp. 151-160, 2019. 